Journal of

Information Systems Engineering

and Business Intelligence

Vol.6, No.l, April 2020

Available online at: http://e-journal.unair.ac.id/index.php/JISEBI

\title{
Lexicon-Based Indonesian Local Language Abusive Words Dictionary to Detect Hate Speech in Social Media
}

\author{
Mardhiya Hayaty ${ }^{1)}$, Sumarni Adi'), Anggit D. Hartanto ${ }^{3)}$ \\ 1)2)3) Faculty of Computer Science, Universitas Amikom Yogyakarta, Indonesia \\ Ring Road Utara Condong Catur, Sleman \\ ${ }^{1)}$ mardhiya_hayati@amikom.ac.id, ${ }^{2)}$ sumarni.a@amikom.ac.id, ${ }^{3)}$ anggit@amikom.ac.id
}

\section{Article history: \\ Received 15 January 2020 \\ Revised 5 March 2020 \\ Accepted 12 March 2020 \\ Available online 28 April 2020}

\section{Keywords:}

Abusive Words

Dictionary base

Hate Speech

Lexicon base

\begin{abstract}
Background: Hate speech is an expression to someone or a group of people that contain feelings of hate and/or anger at people or groups. On social media users are free to express themselves by writing harsh words and share them with a group of people so that it triggers separations and conflicts between groups. Currently, research has been conducted by several experts to detect hate speech in social media namely machine learning-based and lexicon-based, but the machine learning approach has a weakness namely the manual labelling process by an annotator in separating positive, negative or neutral opinions takes time long and tiring

Objective: This study aims to produce a dictionary containing abusive words from local languages in Indonesia. Lexicon-base is very dependent on the language contained in dictionary words. Indonesia has thousands of tribes with 2500 local languages, and $80 \%$ of the population of Indonesia use local languages in communication, with the result that a significant challenge to detect hate speech of social media.

Methods: Abusive words surveys are conducted by using proportionate stratified random sampling techniques in 4 major tribes on the island of Java, namely Betawi, Sundanese, Javanese, Madurese

Results: The experimental results produce 250 abusive words dictionary from 4 major Indonesian tribes to detect hate speech in Indonesian social media by using the lexiconbased approach.

Conclusion: A stratified random sampling technique has been conducted in 4 major Indonesian tribes to produce 250 abusive words for hate speech detection using the lexicon-based approach.
\end{abstract}

\section{INTRODUCTION}

Hate speech is a speech toward someone or a group of people that contain hate or anger toward them [1]. There is a relationship of a language [2] with a strong argument to lead to one's opinion so that it can predict the onset of social conflict. At present, people's dependence on internet connections is very high, especially the use of social media [3], provocation is very easily spread and can influence someone to commit illegal acts.

The number of internet user in Indonesia always increase every year. The number of active Internet users in Indonesia is 143 millions users based on the Indonesian Service User Association survey in 2018. On social media, users send their expression and write bad words freely, insulting words, offensive words or hate. The word or sentence is shared with a specific group or individuals can trigger hatred and separation.

On sentiment analysis, hate speech is a negative sentiment. The algorithms, such as Support Vector Machine, Naive Bayes, Random Forest Decision Tree, can be used to do opinion classification and analysis[5]. However, detection of hate speech not only to match word-to-word, but also to every language has different informal form and grammar.

Indonesia has 1340 tribes, and Javanese spread in almost every territory of Indonesia, which is $40 \%$ of the Indonesian population. Other than that, Indonesia has a lot of local languages, and there are 2500 local languages.

\footnotetext{
${ }^{*}$ Corresponding author
} 
Indonesian people use local words as much as $79.5 \%$ and $19,94 \%$ use the Indonesian language to communicate with each other [6]. It is a challenge mainly because Indonesia has so many descriptive words used in everyday life.

Several studies had been conducted to detect hate speech, one of which is using a machine learning approach. These work compare the performance machine learning algorithms. Random Forest Decision Tree has the best performance with F-measure $93.5 \%$ when using word n-gram feature

A similar study had done with a machine learning approach. The research conducted by [8] and [9] used the naive Bayes algorithm to detect hate speech. The experiment result showed that using two labels was able to give $70 \% \mathrm{~F} 1-$ score, but using two labels gave the best results of more than $80 \%$. The work of detection hate speech had done for multilingual with the method of translated and without translated [10] (identification of the language using a machine learning approach). The non-translated method gives the best performance compared to the translated method. However, the non-translated method to be considered because of needs high cost for data collection and annotations while the translated method using google translate gives poor results because of the ambiguity of the translation results.. Language becomes an essential factor in getting the best efficiency. Research on the use of emoticons [11] in a statement also influences sentiment analysis

One of the weaknesses of the machine learning approach is that the manual labelling process by an annotator to separate negative or positive labels requires a long time, tiring, and subjective [12]. The lexical-based is used to overcome the weaknesses of the machine learning approach. Lexical base is very dependent on the meaning of the language contained in dictionary words [13]. The wealth of words in the dictionary is essential. This paper proposes a dictionary making that contains abusive words using local languages in Indonesia by collecting rude or insulting words through questionnaires that have been filled.

\section{METHODS}

\section{A. Hate speech in social media}

Humans, as social beings, interact and communicate with others through language. They use various expressions to express their feelings like anger, hate, disappointment, displease or even hostility so that others also feel angry and hate.

Social Media is microblogging which provides a virtual life for people to express their feelings, opinions and beliefs openly [14]. Social media like Facebook, Instagram, Twitter are ideal places for Internet users to share stories of daily life, provide and obtain information and spread it, spreading information on social media can be positive or negative information [15].

The existence of social networks emerges more features on social networking facilities such as information exchange, information sharing, news posting and so on, in which it has an impact on increasing the freedom of speech, racist words, cyber terrorism, and extremism [16].

The use of harsh words on social media triggers the increase of cyberbullying. Abusive or offensive language is a painful speech that demeans someone [17]. Cyberbullying causes many social problems [18] such as inter-ethnic disputes.

\section{B. Forms of hate speech in Indonesian}

According to Great dictionary Bahasa Indonesia (2008:633): Word is a language element spoken or written as a unity of feelings and thoughts. It also defines as a morpheme or a combination of morphemes or the smallest unit. The word is a sense of speech. In the written language, the word is express as a composition of the letters - the alphabetic letters that contain obvious meaning (EYD, 21:2003).

Swearing is a cruel word (mean and others) because of anger (annoyance, disappointment, etc.), insults, curses, and remorse (KBBI, 1526: 2008). Swearing may makes people evil, to slander, to revile, to denounce, to criticize, to curse, to curse people because they feel they have been treated unfavourably (KUBI, 1336: 2007) [19].

There is an element of anger [20] in a person that encourages negative emotions such as feelings of disappointment, sadness, and hatred. Words that contain curse, harsh, or hateful meanings consist of into several categories [19] considered as animals; for example: pigs, monkeys, rascals, and others, associated with a lack of physical characteristics of a person; for example: pug, dower, bald, gawking, based on adjectives; like stupid, stupid, whacky, trashy and many more.

\section{Sentiment analysis}

Sentiment Analysis or opinion mining provides the assessment or opinion of a person to the subject, product, or event of the data set. For example, especially in the field of services, customer opinion analysis is indispensable for 
the evaluation of products or services that they produced. Similarly, the government used sentiment analysis to measure the public's response to public facilities that have an impact on the improvement of community facilities.

Sentiment analysis is a technique to identify an opinion expressed by the text [21]. The purpose of sentiment is to classify a commentary into a negative, positive, or neutral impression, and the conclusion can describe one's feelings, emotions [5]. The structure of language in the world varies, text-preprocessing is needed to produce basic words through the process of stopwords removal and stemming [22]

There are two main approaches of sentiment analysis, namely machine learning and lexicon-based [23]. The machine learning method uses a machine-learning algorithm to classify data; in this approach, it consists of a collection of training data for which each record is labelled to a class. While the lexicon-based method uses word dictionaries by matching words in the text with words in the dictionary to find the polarity [5].

\section{Lexicon based}

For the lexical approach, a dictionary is prepared to store the polarity values of lexicons. For calculating polarity of a text, the polarity score of the text will be checked. If the score is presented in the dictionary, then it is added to get an 'overall polarity score'. For example, if a lexicon matches a word marked as positive in the dictionary, then the total polarity score of the text is increased. If the overall polarity score of a text is positive, then that text is classified as positive. Otherwise, it is classified as negative. Though this approach seems very basic, variants of this lexical approach have been reported to have considerably high accuracy [21].

The lexicon-based approach relies on words and language to analyze text. The approach can be used for information retrieval and sentiment analysis. There are two lexicon-based methods namely corpus-based and dictionary-based [5].

The dictionary-based is a lexicon-based method that uses words contained in the dictionary to determine whether the sentence contains negative or positive opinions [24], while the corpus-based approach detects opinions with syntactic patterns. With this method, the lexicon contains words which are more in tune [25] and have different degrees of value. Dictionary-base prioritizes words while corpus-base focuses on the meaning of words.

\section{E. Method}

The step-by-step used in this work can be seen in Fig. 1.

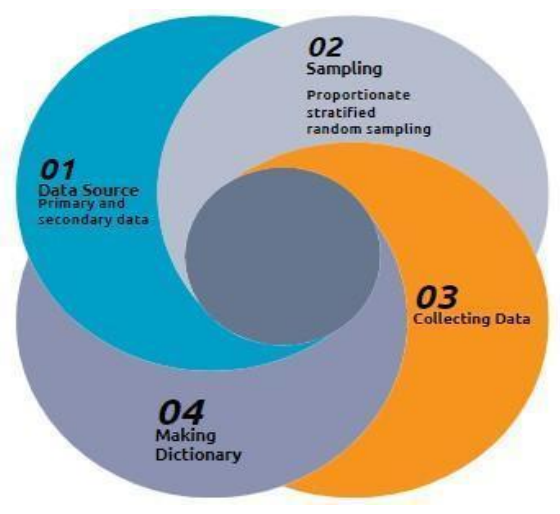

Fig 1. Workflow

This study uses two data sources, namely primary data and secondary data. Primary data come from respondents or samples from a population. The secondary data provides data on the number of ethnic populations which were the results of a population census published by the Indonesian Statistics Agency in 2010 and 2019.

Based on data obtained from secondary data sources showed that the population of Indonesia was in Java island with a percentage of almost 50\% with the largest tribes exists in Java island, namely the Betawi, Sundanese, Javanese and Madurese. The sampling technique uses probability sampling that provides equal opportunities for each element (member) of the population to be selected as a sample member, sample as a representative of a population [26].

The process of collecting harsh words data through an open questionnaire [27] where respondents were asked to write whatever rant they know. Questionnaire dissemination was carried out in various ways, namely by giving 
directly to respondents, as well as through social media such as Google form, Facebook, WhatsApp and other social media.

Besides, a confirmability test was conducted to assess the objectivity of the study. The research is objective if it has been agreed by many people, this test by conducting interviews with community leaders. The dictionaries adapted to technological requirements so that it can detect hate speech on a lexicon base-based social media using dictionary.

\section{RESUlts}

The population is taken from the ethnic groups (Betawi, Sundanese, Javanese, Madurese) on the island of Java consisting of 5 provinces (DIY, DKI Jakarta, West Java, Central Java, East Java). Sampling with the probability sampling method, because of the heterogeneous characteristics of the population, the sample is taken using the proportionate stratified random sampling method. Proportionate stratified random sampling will count the number of sampling by the proportions of each group[28]. The calculation of the number of samples using the Slovin formula is shown in equation 1 [29].

$$
n=\frac{N}{N\left(e^{2}\right)+1}
$$

Where equation (1) is $n=$ number of sample, $N=$ number of population, $e=$ error rate

From the calculation, the error rate is $5 \%$ from 400 respondents. The calculation of the number of samples based on the value of proportions for each tribe. The population proportion value is calculated by the number of samples divided by the population that is equal to 0.000003282297949 . The number of samples each obtained from the calculation of the proportion of the population multiplied by the population per term. The results are presented in Table 1.

TABLE 1.

SAMPLING NUMBER PER-ETHNIC GROUP

\begin{tabular}{rrrr}
\hline Ethnic Group & Population & Proportion & $\begin{array}{r}\text { Minimum Sampling } \\
\text { number }\end{array}$ \\
\hline Betawi & 5.385 .578 & 0.000003282297949 & 18 \\
\hline Sundanese & 32.809 .319 & 0.000003282297949 & 108 \\
\hline Javanese & 77.007 .371 & 0.000003282297949 & 252 \\
\hline Madurese & 6.663 .573 & 0.000003282297949 & 22 \\
\hline
\end{tabular}

The number of real respondents at the time of data collection exceeds the minimum amount of sampling that has been determined that is 863 respondents or an increase of more than $100 \%$. The more sample sizes close to the population, the more accurate the data obtained. The data can be seen in Table 2.

TABLE 2.

REAL RESPONDENTS NUMBER

\begin{tabular}{rrrrr}
\hline Ethnic groups & Respondents Number & Badwords Amount Chosen by Respondents & Badwords Number \\
\hline Betawi & 27 & 27 & 17 \\
\hline Sunda & 126 & 1002 & \\
\hline Jawa & 574 & 168 & 121 \\
\hline Madura & 136 & 56 & \\
\hline Total & $\mathbf{8 6 3}$ & $\mathbf{2 5 0}$ \\
\hline
\end{tabular}

Respondents can write more than one rude word so that any respondents possibly write the same bad word as shown in Table 2. On the results of data collection for dirty words in the Betawi language, there are 27 respondents with 17 words. The words "bangsat", "kampret" are categorized roughly and have the biggest percentage of above $10 \%$. The percentage for each word can be seen in Fig 2. 


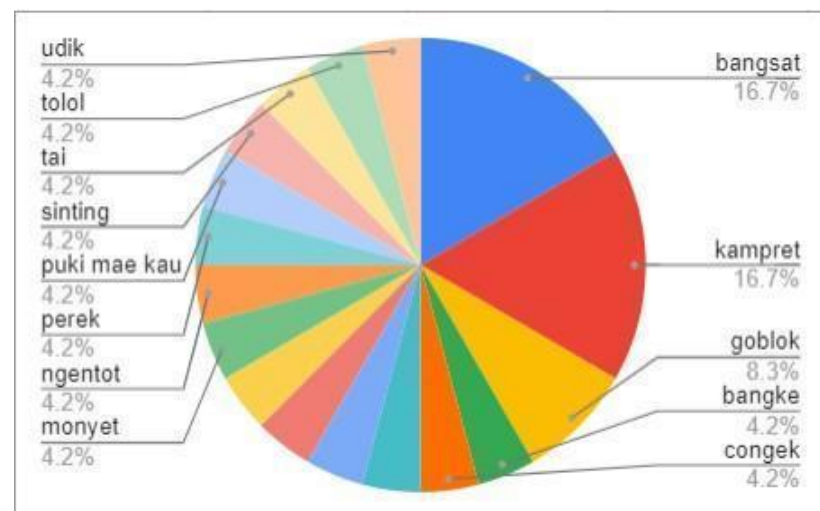

Fig 2. Bad words in "Betawi" language

In Sundanese, the words "kehed", "koplok", "anying", "jurig" have the largest percentage chosen by respondents above $5 \%$ of 56 dirty words. Fig 3 is an overview of the Sundanese Badwords..

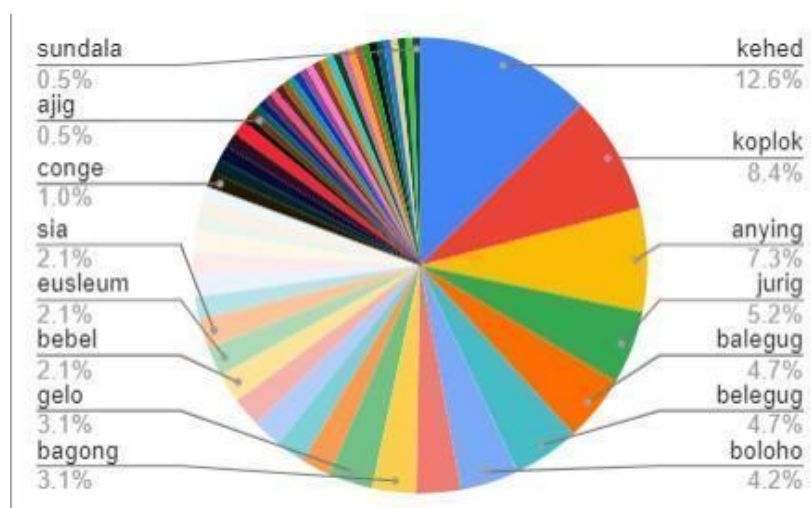

Fig 3. Bad words in "Sundanese"

121 abusive Javanese words have been collected by respondents. The words "asu", "bajingan", "goblog", "kontol" were the most frequently chosen word with a percentage above $5 \%$.

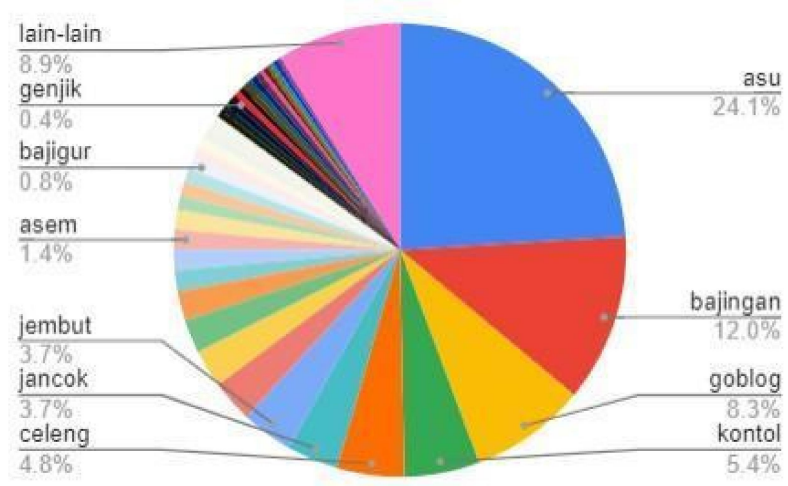

Fig 4. Badwords in "Javanese"

The understanding of abusive language in Madurese is dominated by the words "asu", "bajingan", "jancok", "goblog" with the percentage chosen by respondents above 5\% of 56 words Madurese rant. The percentage for each word can be seen in Fig 5 . 


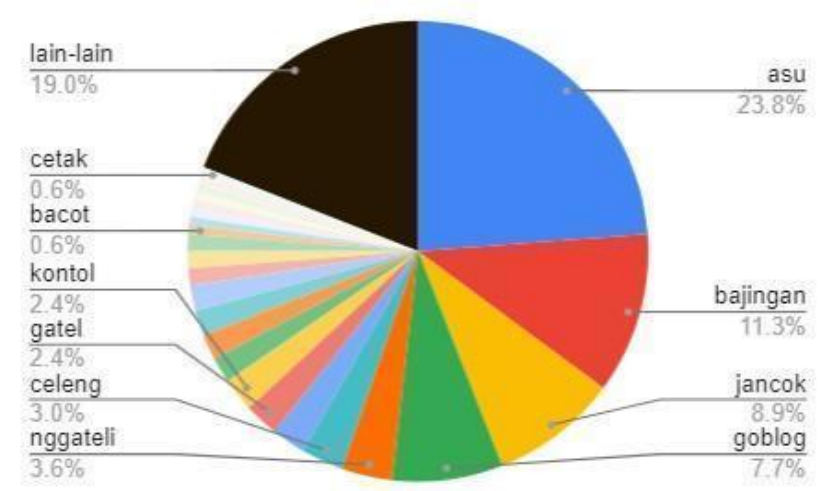

Fig 5. Badwords in "Madurese"

\section{DISCUSSION}

According to the results of data collection, there are similarities of dirty words in the languages of the regions of Java, Madura and Betawi such as "asu", "bajingan", "goblok". According to interviews conducted with community leaders that there is a mixture of cultures within the tribe so there is the use of the same language. Abusive words are addressed to someone is to insult the person by saying him/her like an animal for example"anjing", "anjir", "babi", "monyet". Research [19] revealed some harsh words equating humans like animals. Besides, the writing of harsh words is described with high intonation like an exclamation point "!" to express anger, hatred, and disappointment.

To detect whether a sentence has a negative tendency or not is not just matching words, but the meaning of the entire contents of the sentence. Besides, the use of language in several regions in Indonesia is different. Javanese tribe divides the use of language into ngoko, krama, and krama inggil. The use of words (rough or not) in the Ngoko category will seem normal or not rude if directed to the talker of the same age, but different interpretations when the ngoko words are used to the elderly or respected person in society, the word will seem to be rude or even very rude to some people.

Unlike the Osing tribe in East Java, the culture of the Osing tribe does not differentiate the use of language based on age, but the way of their speaking is just the same for any age.

Speaking with different volume can affect the assessment of whether the person is speaking harshly or not. High sound volume with clear intonation of some regions or tribes is something normal, for example in the island of Borneo or tribes in Papua. With a demographic and geographic background such as the area range, a small number of inhabitants, far apart residential locations forcing them to talk loud even almost screaming so the message can be conveyed. Speaking loudly even like people shouting for people who live in crowded areas like on the island of Java can be interpreted as a language that is rude, impolite to say.

Someone talking with facial expressions and certain body gestures can be distinguished whether the talker is in a reasonable condition or not that impacts the choice of words, for example, sulking facial expressions, blush red with gestures pointing fingers, stomping feet means that person is in a state angry and use harsh words and lead to feelings of hate. However, if the use of abusive words is followed by a smile, laughter can be interpreted as a rough word that is used as a joke.

If we communicate directly it will be easier to judge whether it contains hate speech or not through indications of the use of language, culture, intonation, voice volume, facial expressions and body gestures. Then what about the use of language in social media? In social media, in this case the users do not meet directly. They can not see the surrounding conditions that may affect the other person, free expression, free to write something that may unconsciously hurt the feelings of people even do not know each other, so hate speech on social media is very high. For some people, the act of deliberately expressing harsh words through social media is a surefire way to embarrass others because they are motivated by feelings of revenge between the two parties to lead public opinion to hate someone or a certain group which ultimately leads to division. Although this is a form of violation of the law, this is a challenge for researchers on how to detect hate speech.

Based on observations that have been made to someone's language style in writing abusive words on text-based social media is the use of capital letters, it aims to emphasize that the written words have an element of feeling angry. For example in the Sundanese rough word "anjir" to "ANJIR" (mean dog). It has a meaning that equates humans with animals, but to emphasize that the person is truly likened to a dog, then write a rude word to be "anjir loe" or "ANJIR LOE" (you are a dog). 
TABLE 3.

LIST OF BADWORDS FROM ETHNIC GROUPS

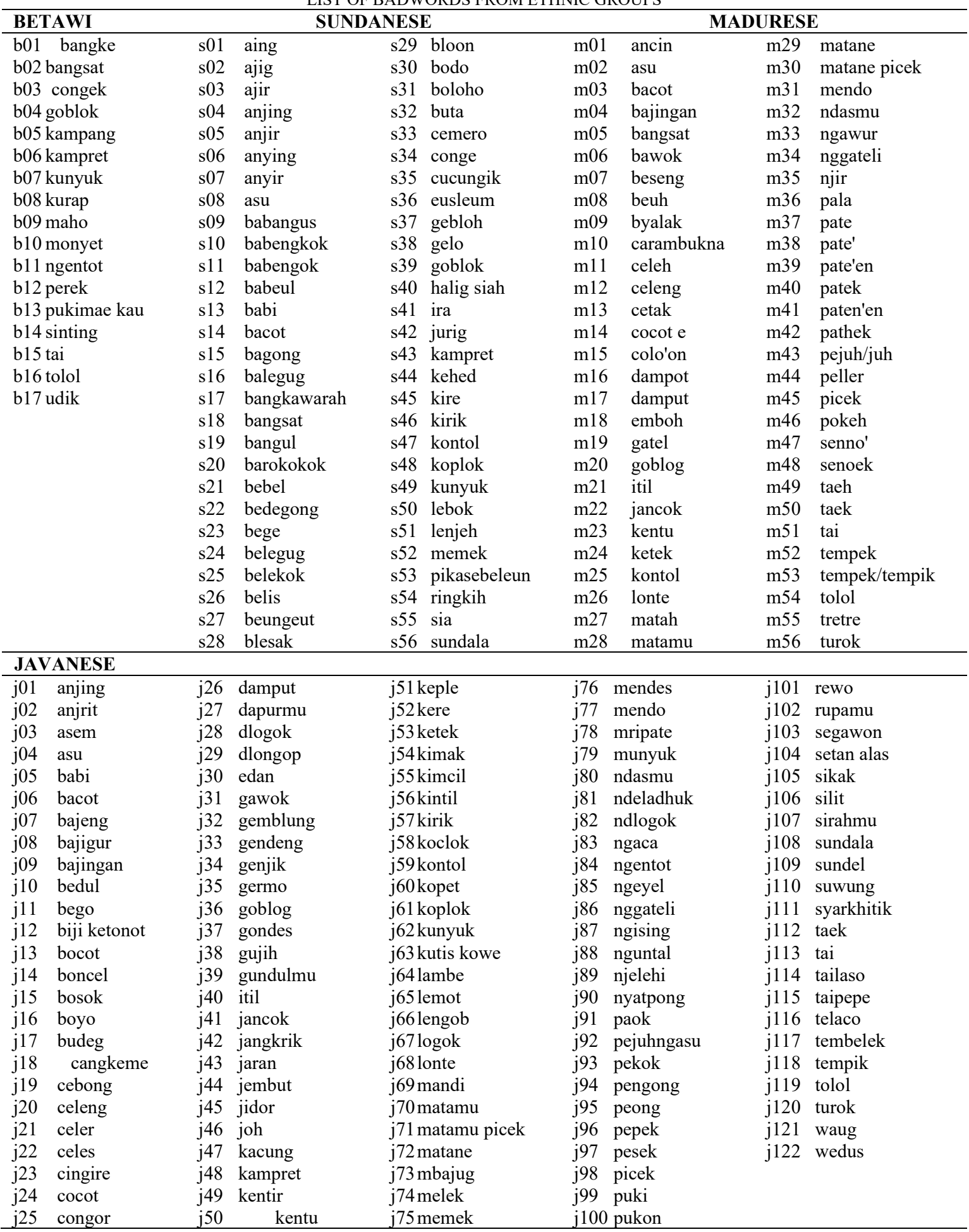

If the pronunciation of harsh words directly by way of intonation is extended and loud noises are different from the way of writing on social media. Text is written by adding letters to basic words such as "kontol" to "kontoooool" or "kontoll1ll" (male genitals). The word "budeg" becomes "budeeeeggg" (deaf, can not hear). 
The collection of 250 words of data originating from 4 regions or tribes in Indonesia, these words are basic and do not yet have an additional degree of hatred or anger as explained above. The word "anjir" is only written "anjir" not "ANJIR" or "anjiiir", as well as other harsh words. This can be overcome by another lexicon base method, which is corpus-based or by pre-processing for slang. The following is a list of dirty words as in Table 3.

One challenge to ensure sentences have hate speech is that sentences arranged in paragraphs have different goals and objectives, for example, the word "asu (dog)" on the sentence "....Sikapmu menyakitkan saya, kamu itu benerbener asu!...(your attitude hurts me, you are really dog!)" and another sentence, "....akhir-akhir ini, kampung kami banyak sekali asu berkeliaran.......(lately, our village has a lot of wild dogs....)." The first sentence is categorical of hate speech, while the word "asu" on the second sentence means just information. It is difficult to detect whether a sentence has a hateful speech or not based on the word's existence without interpreting the entire sentence.

Indonesia consists of 2500 tribes so that it has diverse languages as a treasure, including harsh words. Besides that, regional languages contain different meanings of a phrase or sentence. This research only produced a dictionary of abusive words. The process of detecting hate speech automatically is not carried out. Open up opportunities for other researchers to conduct in-depth research on this topic with better methods.

\section{CONCLUSIONS}

This study was successful to produce a dictionary consisting of dirty words in regional languages namely Betawi, Sundanese, Javanese and Madurese totalling 250 words. Several harsh words have a high percentage such as bangsat, kampret, goblok, kehed, koplok, asu, bajingan. These words are well-known words to the public as harsh words, but along with the mixing of cultures, cultural shifts are very likely the words are not rude because people often use these words. Besides the meaning of words in a sentence will have a different understanding than just words. This research has been carried out observations through interviews with several local community leaders and looking for appropriate library sources.

\section{REFERENCES}

[1] Z. Al and M. Amr, "Automatic hate speech detection using killer natural language processing optimizing ensemble deep learning approach," Computing, no. 0123456789, 2019.

[2] M. Makrehchi, "The correlation between language shift and social conflicts in polarized social media," Proc. - 2014 IEEE/WIC/ACM Int. Jt. Conf. Web Intell. Intell. Agent Technol. - Work. WI-IAT 2014, vol. 2, pp. 169-194, 2014.

[3] Y. Rao, J. Lei, L. Wenyin, Q. Li, and M. Chen, "Building emotional dictionary for sentiment analysis of online news," World Wide Web Internet Web Inf. Syst., pp. 723-742, 2014.

[4] A. P. J. I. Indonesia, "Buletin APJII Edisi 22 Maret 2018," Bul. APJII, 2018.

[5] W. Medhat, A. Hassan, and H. Korashy, "Sentiment analysis algorithms and applications: A survey," Ain Shams Eng. J., vol. 5, no. 4, pp. 1093-1113, Dec. 2014.

[6] Kewarganegaraan, suku bangsa, Agama, dan bahasa sehari-hari Penduduk Indonesia. Hasil Sensus Penduduk 2010. Badan Pusat statistik, Jakarta-indonesia, 2011.

[7] I. Alfina, R. Mulia, M. I. Fanany, and Y. Ekanata, "Hate speech detection in the Indonesian language: A dataset and preliminary study," in 2017 International Conference on Advanced Computer Science and Information Systems, ICACSIS 2017, 2018.

[8] N. R. Fatahillah, P. Suryati, and C. Haryawan, "Implementation of Naive Bayes classifier algorithm on social media (Twitter) to the teaching of Indonesian hate speech," in Proceedings - 2017 International Conference on Sustainable Information Engineering and Technology, SIET 2017, 2018.

[9] M. O. Ibrohim and I. Budi, "A Dataset and Preliminaries Study for Abusive Language Detection in Indonesian Social Media," Procedia Comput. Sci., vol. 135, pp. 222-229, Jan. 2018.

[10] M. O. Ibrohim and I. Budi, "Translated vs Non-Translated Method for Multilingual Hate Speech Identification in Twitter," Int. J. Adv. Sci. Eng. Inf. Technol., vol. 9, no. 4, pp. 1116-1123, 2019.

[11] D. Alita, S. Priyanta, and N. Rokhman, "Analysis of Emoticon and Sarcasm Effect on Sentiment Analysis of Indonesian Language on Twitter," J. Inf. Syst. Eng. Bus. Intell., vol. 5, no. 2, pp. 100, 2019.

[12] F. Hemmatian and M. Karim, "A survey on classification techniques for opinion mining and sentiment analysis," Artif. Intell. Rev., vol. 52, no. 3, pp. 1495-1545, 2019.

[13] A. Jurek, M. D. Mulvenna, and Y. Bi, "Improved lexicon - based sentiment analysis for social media analytics," Secur. Inform., 2015.

[14] N. D. T. Ruwandika and A. R. Weerasinghe, "Identification of Hate Speech in Social Media," 2019.

[15] T. L. Sutejo and D. P. Lestari, "Indonesia Hate Speech Detection Using Deep Learning," in International Conference on Asian Language Processing (IALP), 2019, pp. 39-43.

[16] N. Chetty and S. Alathur, "Hate speech review in the context of online social networks," Aggress. Violent Behav., vol. 40, pp. 108-118, May 2018.

[17] M. Wiegand, J. Ruppenhofer, A. Schmidt, and C. Greenberg, "Inducing a Lexicon of Abusive Words - a Feature-Based Approach," Proc. 2018 Conf. North Am. Chapter Assoc. Comput. Linguist. Hum. Lang. Technol., vol. 1, pp. 1046-1056, 2018.

[18] H.-S. Lee, H.-R. Lee, J.-U. Park, and Y.-S. Han, "An abusive text detection system based on enhanced abusive and non-abusive word lists,” Decis. Support Syst., vol. 113, pp. 22-31, Sep. 2018.

[19] I. B. Sumadyo, "Sekilas tentang Bentuk Umpatan dalam Bahasa Indonesia," in 2 nd International Seminar on Quality and Affordable Education, 2013. 
[20] M. Ekawati, "Kesantunan Semu pada Tindak Tutur Ekspresif Marah dalam Bahasa Indonesia,” Adab. J. Bhs. dan Sastra, vol. 1, no. 1, pp. 1-22, 2018.

[21] C. Bhadane, H. Dalal, and H. Doshi, "Sentiment Analysis: Measuring Opinions,” Procedia Comput. Sci., vol. 45, pp. 808-814, Jan. 2015.

[22] A. W. Pradana and M. Hayaty, "The effect of stemming and removal of stopwords on the accuracy of sentiment analysis on indonesianlanguage texts," Kinet. Game Technol. Inf. Syst. Comput. Network, Comput. Electron. Control, vol. 4, no. 3, 2019.

[23] W. Kaur, V. Balakrishnan, O. Rana, and A. Sinniah, "Liking, sharing, commenting and reacting on Facebook: User behaviors' impact on sentiment intensity," Telemat. Informatics, Dec. 2018.

[24] S. Taj, B. B. Shaikh, and A. Fatemah Meghji, "Sentiment analysis of news articles: A lexicon based approach," 2019 2nd Int. Conf. Comput. Math. Eng. Technol. iCoMET 2019, no. February, 2019.

[25] N. D. Gitari, Z. Zuping, H. Damien, and J. Long, "A lexicon-based approach for hate speech detection," Int. J. Multimed. Ubiquitous Eng., vol. 10, no. 4, pp. 215-230, 2015.

[26] C. Teddlie and F. Yu, "Mixed Methods Sampling: A Typology Journal of Mixed Methods Research," J. Mix. Methods Res., vol. 1, no. 1, pp. 77-100, 2007

[27] E. L. Slattery, C. C. J. Voelker, B. Nussenbaum, J. T. Rich, R. C. Paniello, and J. G. Neely, "A practical guide to surveys and questionnaires," Otolaryngol. - Head Neck Surg., vol. 144, no. 6, pp. 831-837, 2011.

[28] C. Fan, P. Zhang, and V. Sun, "Natural Disaster Information Statistics Study Based on Stratified Random Sampling Survey Statistical Methods," in 2012 IEEE International Conference on Granular Computing Natural, 2012, vol. 00, pp. 1-4.

[29] G. Sevilla, J. A. Ochave, T. G. Punsalan, B. P. Regala, and G. G. Uriarte, Research Methods. 2007. 